\title{
Ability to Move Normally
}

National Cancer Institute

\section{Source}

National Cancer Institute. Ability to Move Normally. NCI Thesaurus. Code C121370.

The quality of being able to change positions within regular limits. 